\title{
Inflammatory biomarkers and their correlates among hypertensive population in two tertiary hospitals in Sokoto, Nigeria
}

\author{
Mohammed HarunaYELDU ${ }^{*}$, Bala MalamYALE ${ }^{1}$, Shehu Abubakar AKUYAM ${ }^{1}$ and \\ Simeon Alabi ISEZUO ${ }^{2}$

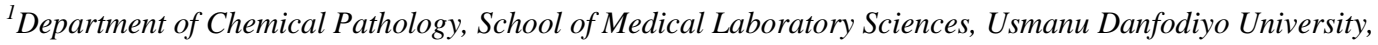 \\ Sokoto, PMB 2346 Sokoto, Nigeria. \\ ${ }^{2}$ Department of Medicine, Faculty of Clinical Sciences, College of Health Sciences, Usmanu Danfodiyo \\ University, Sokoto, PMB 2346 Sokoto, Nigeria. \\ *Corresponding author; E-mail: mhyeldu@gmail.com; mhyeldu@yahoo.com
}

\begin{abstract}
Several cross-sectional studies suggest that inflammation may be involved in the development of hypertension. The objective of the study was to examined inflammatory biomarkers - C-reactive protein (CRP), plasma fibrinogen and their correlates among hypertensive population in two tertiary hospitals in Sokoto, Nigeria. A total of 316 hypertensive patients aged 25 to 76 years and 158 age- and sex- matched apparently healthy normotensive subjects seen in the Medical and Out Patient Departments of Usmanu Danfodiyo University Teaching Hospital and Specialist Hospital, Sokoto, Nigeria were included in the study between July and December, 2016. Blood pressure and anthropometric measurements were done using standard techniques. Serum CRP and plasma fibrinogen concentrations were estimated by ELISA and assay kit respectively. The results showed that, CRP, fibrinogen, body mass index (BMI), systolic blood pressure (SBP) and diastolic blood pressure $(\mathrm{DBP})$ were significantly $(\mathrm{p}<0.001)$ higher in hypertensive subjects than normotensive subjects. Significant positive correlations were established between BMI and each of CRP and fibrinogen in hypertensive patients. In conclusion, the results in the current study demonstrates that serum CRP and plasma fibrinogen levels are elevated in hypertensive subjects and positively correlated with BMI. Thus routine measurement of serum CRP and plasma fibrinogen can be a potential tool for early identification of individuals at the risk for development of hypertension and cardiovascular diseases.
\end{abstract}

(C) 2018 International Formulae Group. All rights reserved.

Keywords: Hypertension, C-reactive protein, fibrinogen, Sokoto.

\section{INTRODUCTION}

Hypertension is one of the most important public health problem in developing countries and one of the major risk factors for cardiovascular diseases. The global burden of hypertension is enormous (Kearney et al., 2004), and has been recognized as the most common cardiovascular disorder and a leading cause of morbidity and mortality in both developed and developing countries (Goyal and Sarwate, 2014). Elevated plasma level of low density lipoprotein (LDL) fraction that contributes to hyperlipidaemia has been implicated in the development of atherosclerosis and progression of cardiovascular diseases (Onyeali et al., 2010). 
Hypertension is also characterized by alterations in the structure and function of the cell membrane, and is often associated with metabolic abnormalities including dyslipidaemia (Ikewuchi et al., 2011).

The reported global prevalence of hypertension varies with the lowest prevalence in rural India $(3.4 \%$ in men and $6.8 \%$ in women) and highest in Poland (68.9\% in men and $72.5 \%$ in women; (Kearney et al., 2004). In sub-Sahara Africa, the prevalence is reported as $32.6 \%$ (Addo et al., 2007). The prevalence in Nigeria varied from $11 \%$ to 45\% (Osuji et al., 2012). In Sokoto, the reported prevalence of hypertension is $24.8 \%$ (Isezuo, 2015).

A growing body of evidences has shown that vascular inflammation may play a critical role in the initiation and development of hypertension ( $\mathrm{Li}$ et al., 2005). Hypertension is thought to be an inflammatory disorder (Bautista et al., 2001; Li et al., 2005) and systemic inflammation may play an important role in the pathogenesis of endothelial dysfunction, leading to functional and structural changes in the endothelium which are more apparent in the early stages of hypertension (Sesso et al., 2015). A state of inflammation also play a key role in the pathogenesis of a number of chronic inflammatory systemic diseases, which include atherosclerosis, psoriasis, systemic lupus erythematosus and rheumatoid arthritis (Reshma et al., 2011).

Some cross-sectional studies reported higher plasma C-reactive protein (CRP) concentrations with increases in blood pressure (BP) in treated or untreated patients with hypertension than in normotensive individuals (Pockley et al., 2002; Bautista et al., 2004). The association between elevated CRP levels and high BP may have three different pathophysiological explanations. Several studies suggest that CRP may induce a decrease in endothelium dependent relaxation, a potential risk factor for hypertension. High BP may however induce inflammation and raise CRP levels (Bautista et al., 2005). On the other hand, the association could be confounding, because
CRP and high BP share several risk factors such as lower socio-demographic position, lack of physical activity, smoking and truncal obesity (Bautista et al., 2005). Higher CRP concentrations among hypertension might be explained by a clustering of common positive CRP covariates (age, female sex and increased body mass index and lipid concentrations) among hypertensive patients (JNC, 2003). The clinical relevance of CRP determination in subjects without clinically overt ischemic heart disease is still controversial. A report of the Reykjavik study showed that CRP is an independent predictor of coronary heart disease, though the CRP-associated odds ratio was lower than that of established cardiovascular risk factors such as systolic blood pressure (SBP), smoking and elevation of total cholesterol (TC) (Danesh et al., 2004).

Plasma fibrinogen is an important component of the coagulation cascade, as well as a major determinant of blood viscosity and blood flow. Increasing evidence from epidemiological studies suggests that elevated plasma fibrinogen levels are associated with an increased risk of cardiovascular disorders, including ischaemic heart disease, stroke and other thromboembolism (Kamath and Lip, 2003). It may promote a prothrombotic or hypercoagulable states, and may in part explain the risk of stroke and thromboembolism in conditions such as atrial fibrillation (Hajat et al., 2001). The use of inflammatory markers in predicting the risk of cardiovascular disease is increasingly gaining attention. However, the relationship between CRP and fibrinogen in hypertension has not been studied in Sokoto, Nigeria. The current study examined markers of inflammationCRP and fibrinogen for their association with blood pressure and body mass index in hypertensive population of African descent in Sokoto.

\section{MATERIALS AND METHODS Study area}

Blood samples were collected at Usmanu Danfodiyo University Teaching Hospital, and the Specialist Hospital. Both medical facilities are located in Sokoto, 
Northern Nigeria. Ethical approval was obtained from Ethics and Research Committee of each Hospital prior to commencement of the study. Sokoto State is located at the extreme part of North-Western Nigeria between longitude $3^{\circ}$ and $7^{\circ}$ east and between latitude $10^{\circ}$ and $14^{\circ}$ north of the equator. It shares borders with Niger Republic to the North, Kebbi State to the South West and Zamfara State to the East (SSBD, 2007). The State covers a total land area of about 32,000 square kilometres and a population of 4,602298 million based on 2013 projection (UNFPA, 2013). Sokoto State has semi-arid climate and vegetation is largely Sudan Savannah with an annual rainfall between 500 - $1300 \mathrm{~mm}$ and temperature range between 15 and over $40{ }^{\circ} \mathrm{C}$ during warm days (SSBD, 2007).

\section{Study subjects and blood sample collection}

A total of 474 subjects were recruited for the study. These consisted of 316 diagnosed adult male and female hypertensive patients and 158 age- and sex- matched apparently healthy normotensive subjects (controls). Blood samples were collected from hypertensive patients attending Medical and outpatient Clinics, aged 25 to $\geq 76$ years, while the controls were recruited from a population of people living in Sokoto metropolis. Each subject's consent was sought and obtained after the purpose of the study was explained to each of them. Eligibility criteria for the hypertensive patients included those who aged 25 to 76 years with BP values of $140 / 90 \mathrm{mmHg}$ and above confirmed on two different occasions and provided written informed consent. Study subjects were ineligible if they have any of the following: a) metabolic disorders such as diabetes mellitus, among others, as well as organ diseases such as liver, kidney and gastrointestinal tract (GIT) diseases, b) be pregnant, c) smoke cigarette, abuse alcoholic, d) those who decline to give consent for inclusion.

During blood sample collection, $3 \mathrm{ml}$ of venous blood sample was collected from each selected subject using a sterile disposable syringe and needle. Two (2) $\mathrm{ml}$ of blood was transferred to plain tubes and allowed to clot at room temperature after which it was centrifuged at $3000 \mathrm{rpm}$ for 5 minutes to obtain a clear unhaemolyzed serum. The sera were harvested and placed in another plain tube and rapidly stored at $-20{ }^{\circ} \mathrm{C}$ until the time for analysis. One millilitre of blood was transferred into a bottle containing $111 \mu 1$ trisodium citrate and centrifuged immediately at $300 \mathrm{x} \mathrm{g}$ for 10 minutes and the plasma transferred to plastic container and immediately frozen at $-20{ }^{\circ} \mathrm{C}$ until assayed.

\section{Study design}

This is a cross sectional study. All the hypertensive patients were evaluated by the Consultant Physicians. At enrolment a structured-interviewer administered questionnaire was used to document the subject's demographic and socioeconomic data including age, sex, marital status, occupation, education and presence of any disease among others.

\section{Blood pressure (BP) and anthropometric measurements}

Blood pressure of each subject was measured on a single visit by the Consultant Physician, using a standard mercury sphygmomanometer and appropriate cuff sizes, with the subject in a seated position, and having rested for at least 10 minutes. Three separate readings were taken per subject, after two minutes intervals and the average of the second and third readings recorded. Systolic blood pressure (SBP) and diastolic blood pressure (DBP) were taken at the $1^{\text {st }}$ and $5^{\text {th }}$ Korotkoff sounds respectively (Ijeh et al., 2010).

Anthropometric parameters of the subjects were measured using standard techniques. Subjects were weighted without shoes, and with minimum clothing to the nearest $0.1 \mathrm{~kg}$ by using a regularly calibrated weighing health scale; model ZT 120 (Seca Gmbh and Co., Germany), while for height measurement, the subjects stood erect and barefooted on a regularly calibrated Stadiometer with a movable head piece; 
model 220 (Seca Gmbh and Co., Germany). The head piece was levelled with the skull vault and height of the subjects read and recorded to the nearest $0.5 \mathrm{~cm}$. BMI for each subject was calculated using the following equation: BMI $\left(\mathrm{kg} / \mathrm{m}^{2}\right)=$ Body Weight $(\mathrm{kg}) /$ Height $\left(\mathrm{m}^{2}\right)$ (Sergio et al., 2007).

\section{Serum C - reactive protein and plasma fibrinogen measurements}

Serum concentrations of CRP were estimated by the method described by Chard (1990) using ELISA kit obtained from Labkit Barcelona, Spain. Plasma fibrinogen concentrations were estimated by the assay method described by Schmaier (2012) using kit obtained from Labkit Barcelona, Spain.

\section{Statistical analysis}

The data generated were analyzed using statistical package for social sciences (SPSS) version 20. Continuous variables are expressed as mean plus/minus standard error of the mean (Mean \pm SEM). The results of both the clinical and biochemical parameters obtained from hypertensive patients were compared with those of controls using paired two-tailed student's t-test for matched samples. Correlation of age, BMI and BP with CRP and fibrinogen were carried out using Pearson's linear correlation analysis. A pvalue of less than or equal to $0.05(\mathrm{p} \leq 0.05)$ was considered as significant.

\section{RESULTS}

The demographic and socioeconomic characteristics of hypertensive patients and controls are presented in Table 1. The result indicated a total of 316 hypertensive patients (155 males and 161 females) and 158 apparently healthy subjects (74 males and 84 females) were recruited respectively. Most of the subjects were within the age range of 41 56 years $(43.3 \%)$. Most $(92.8 \%)$ of the subjects were married and were predominantly Hausas $(85.9 \%)$ by tribes with $39.5 \%$ having no formal education.

Table 2 shows the anthropometric values of hypertensive patients and controls. The result indicated significantly $(\mathrm{p}<0.001)$ increased body weight, BMI and waist circumference (WC) in hypertensive patients as compared with controls. The mean height in hypertensive patients were not significantly different $(p=0.117)$ from those of controls. The mean SBP, DBP, CRP and fibrinogen were also significantly $(\mathrm{p}<0.001)$ higher, among hypertensive patients than controls (Table 3).

The correlation coefficient ( $r$ ) of age against CRP and fibrinogen is presented in Table 4. The result showed no significant $(\mathrm{r}=$ $0.027 ; \mathrm{p}=0.629$ and $\mathrm{r}=0.021 ; 0.713$ respectively) correlation between age and each of CRP and fibrinogen in hypertensive patients. A significant $(r=0.157 ; p=0.048)$ positive correlation was established between age and CRP, while an insignificant $(r=$ $0.063 ; \mathrm{p}=0.434)$ negative correlation was observed between age and fibrinogen in controls. The correlation between blood pressure and each of CRP and fibrinogen among hypertensive patients and controls is presented in Table 5. The result indicated no significant correlation between SBP and each of CRP and fibrinogen and between DBP and each of CRP and fibrinogen in both hypertensive patients and controls.

Table 6 and Figures 1-2 shows the correlation of between BMI and each of plasma fibrinogen and serum CRP in hypertensive patients and controls. A significant positive correlation was established between BMI and each of plasma fibrinogen and serum CRP in hypertensive patients, while a significant positive correlation was also established between plasma fibrinogen in control subjects. 
Table 1: Demographic and socioeconomic characteristics of hypertensive patients and controls.

\begin{tabular}{llll}
\hline Characteristics & \multicolumn{2}{l}{ No. of Subjects (N=474) } & Percentage (100\%) \\
\hline Age Class & M (n=229) & $\mathbf{F ~ ( 2 4 5 )}$ & \\
$25-40$ & 34 & 41 & 15.8 \\
$41-56$ & 88 & 117 & 43.3 \\
$57-72$ & 93 & 82 & 36.9 \\
$\geq 73$ & 14 & 5 & 4 \\
Marital Status & & \\
Married & 440 & 92.8 \\
Single & 21 & 4.4 \\
Widowed & 13 & 2.7 \\
Tribe & & \\
Hausa & 407 & 85.9 \\
Yoruba & 22 & 4.6 \\
Igbo & 7 & 1.5 \\
Others & 38 & 8.0 \\
Occupation & & \\
Civil Servants & 151 & 31.9 \\
Business men/women & 29 & 6.1 \\
Artisan & 21 & 4.4 \\
Students & 21 & 4.4 \\
Others & 252 & 53.2 \\
Level of Education & & \\
Tertiary & 147 & 31.0 \\
Secondary & 57 & 12.0 \\
Primary & 83 & 17.5 \\
No Formal Education & 187 & 39.5 \\
\hline Values are number of subjects and percentage in parenthesis; M male; F = female. \\
r.
\end{tabular}

Table 2: Anthropometric values of the study population.

\begin{tabular}{llll}
\hline Variable & Hypertensive Patients $(\mathbf{n}=\mathbf{3 1 6})$ & Controls $(\mathbf{n}=158)$ & P-value \\
\hline Age $($ years $)$ & $53.68 \pm 0.68$ & $52.97 \pm 0.948$ & 0.862 \\
Height $(\mathrm{m})$ & $1.63 \pm 0.0038$ & $1.64 \pm 0.0035$ & 0.117 \\
Weight $(\mathrm{Kg})$ & $71.76 \pm 0.75$ & $63.51 \pm 0.46$ & $<0.001$ \\
BMI $\left(\mathrm{Kg} / \mathrm{m}^{2}\right)$ & $27.13 \pm 0.31$ & $23.54 \pm 0.12$ & $<0.001$ \\
WC $(\mathrm{Cm})$ & $92.89 \pm 0.75$ & $84.42 \pm 0.35$ & $<0.001$ \\
\hline
\end{tabular}

Values are mean \pm Standard error of mean; $\mathrm{n}=$ number of subjects; BMI=body mass index; WC=waist circumference.

Table 3: Blood pressure, C-reactive protein and fibrinogen levels among hypertensive patients and controls.

\begin{tabular}{llll}
\hline Parameters & Hypertensive Patients $(\mathbf{n = 3 1 6})$ & Controls $(\mathbf{n = 1 5 8})$ & P-value \\
\hline SDP $(\mathrm{mmHg})$ & $166.00 \pm 1.39$ & $124.97 \pm 0.95$ & $<0.001$ \\
DBP $(\mathrm{mmHg})$ & $98.44 \pm 0.74$ & $81.57 \pm 0.27$ & $<0.001$ \\
CRP $(\mathrm{mmol} / \mathrm{L})$ & $0.078 \pm 0.01$ & $0.054 \pm 0.01$ & $<0.001$ \\
Fibrinogen $(\mu \mathrm{mol} / \mathrm{L})$ & $16.58 \pm 0.29$ & $8.05 \pm 0.15$ & $<0.001$ \\
\hline
\end{tabular}

Values are mean \pm Standard error of mean; $\mathrm{n}=$ number of subjects; $\mathrm{SBP}=$ systolic blood pressure; $\mathrm{DBP}=$ diastolic blood pressure; $\mathrm{CRP}=\mathrm{C}$-reactive protein. 
Table 4: Correlations between age and each of C-reactive protein and fibrinogen among hypertensive patients and controls.

\begin{tabular}{lllll}
\hline Parameters & \multicolumn{2}{c}{$\begin{array}{c}\text { Hypertensive Patients }(\mathbf{n}=316) \\
\text { Age }\end{array}$} & \multicolumn{2}{c}{$\begin{array}{c}\text { Controls }(\mathbf{n}=158) \\
\text { Age }\end{array}$} \\
& $\mathrm{r}$ & $\mathrm{p}$ & $\mathrm{r}$ & $\mathrm{p}$ \\
\hline CRP & 0.027 & 0.629 & 0.157 & 0.048 \\
Fibrinogen & 0.021 & 0.713 & -0.063 & 0.434 \\
\hline
\end{tabular}

Values are correlation coefficient $(\mathrm{r}), \mathrm{CRP}=\mathrm{C}$-reactive protein and $\mathrm{p}=\mathrm{p}$-value.

Table 5: Correlations between blood pressure and each of C-reactive protein and fibrinogen in hypertensive patients and controls.

\begin{tabular}{|c|c|c|c|c|c|c|c|c|}
\hline \multirow[t]{3}{*}{ Variable } & \multicolumn{4}{|c|}{ Hypertensive Patients $(n=316)$} & \multicolumn{4}{|c|}{ Controls $(n=158)$} \\
\hline & \multicolumn{2}{|c|}{ SBP } & \multicolumn{2}{|c|}{ DBP } & \multicolumn{2}{|c|}{ SBP } & \multicolumn{2}{|c|}{ DBP } \\
\hline & $\mathbf{r}$ & $\mathbf{p}$ & $\mathbf{r}$ & p & $\mathbf{r}$ & $\mathbf{p}$ & $\mathbf{r}$ & $\mathbf{p}$ \\
\hline CRP & -0.046 & 0.412 & -0.035 & 0.536 & 0.047 & 0.556 & 0.086 & 0.284 \\
\hline Fibrinogen & -0.036 & 0.521 & -0.032 & 0.569 & -0.009 & 0.907 & -0.149 & 0.062 \\
\hline
\end{tabular}

Table 6: Correlations between BMI and each of C-reactive protein and fibrinogen among hypertensive patients and controls.

\begin{tabular}{|c|c|c|c|c|}
\hline \multirow[t]{2}{*}{ Variable } & \multicolumn{2}{|c|}{$\begin{array}{l}\text { Hypertensive Patients }(\mathrm{n}=316) \\
\text { BMI }\end{array}$} & \multicolumn{2}{|c|}{$\begin{array}{l}\text { Controls }(n=158) \\
\text { BMI }\end{array}$} \\
\hline & $\mathbf{r}$ & p & $\mathbf{r}$ & $\mathbf{p}$ \\
\hline CRP & 0.251 & $<0.001$ & -0.075 & 0.352 \\
\hline Fibrinogen & 0.335 & $<0.001$ & 0.189 & 0.017 \\
\hline
\end{tabular}

Values are correlation coefficient $(\mathrm{r})$; BMI = body mass index; CRP= C-reactive protein; $n=$ number of subjects $\mathrm{p}=\mathrm{p}$-value.

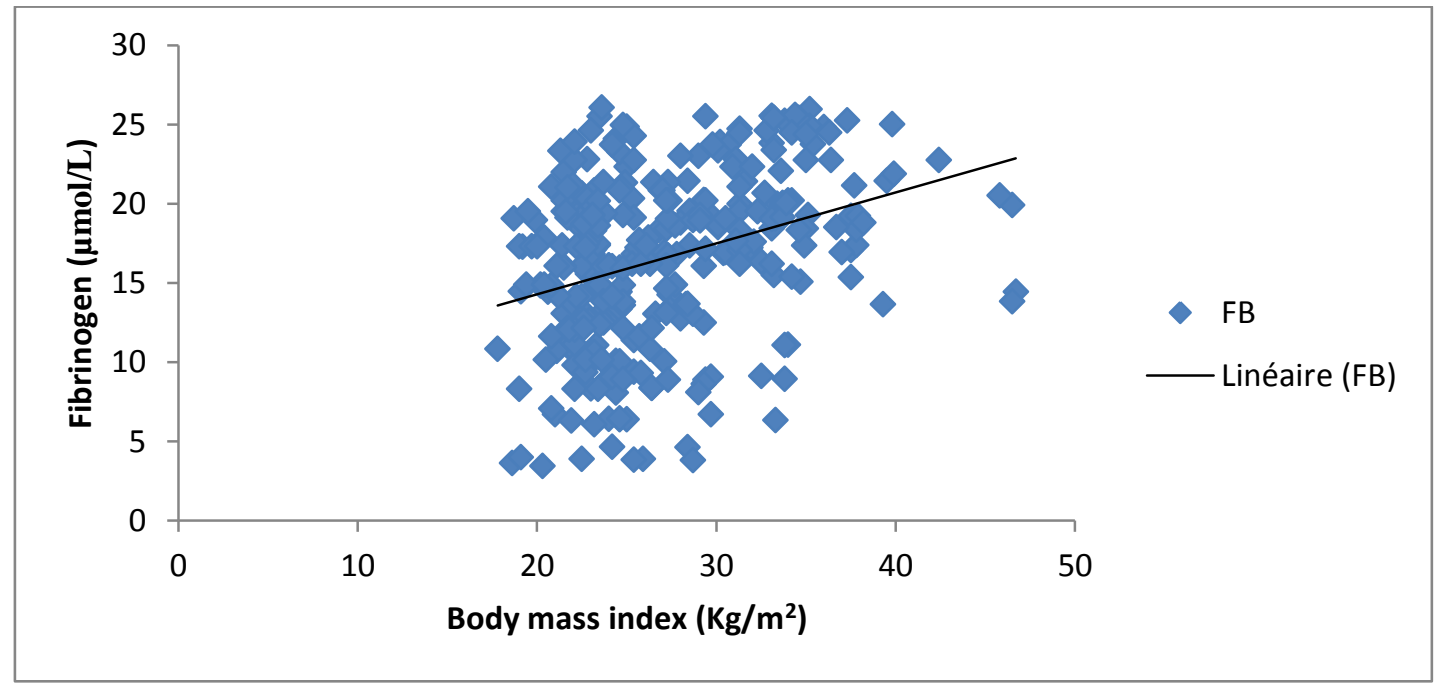

Figure 1: Scatter plot between body mass index and fibrinogen in hypertensive patients $\quad(n=316$, $\mathrm{r}=0.335, \mathrm{p}<0.001)$. 


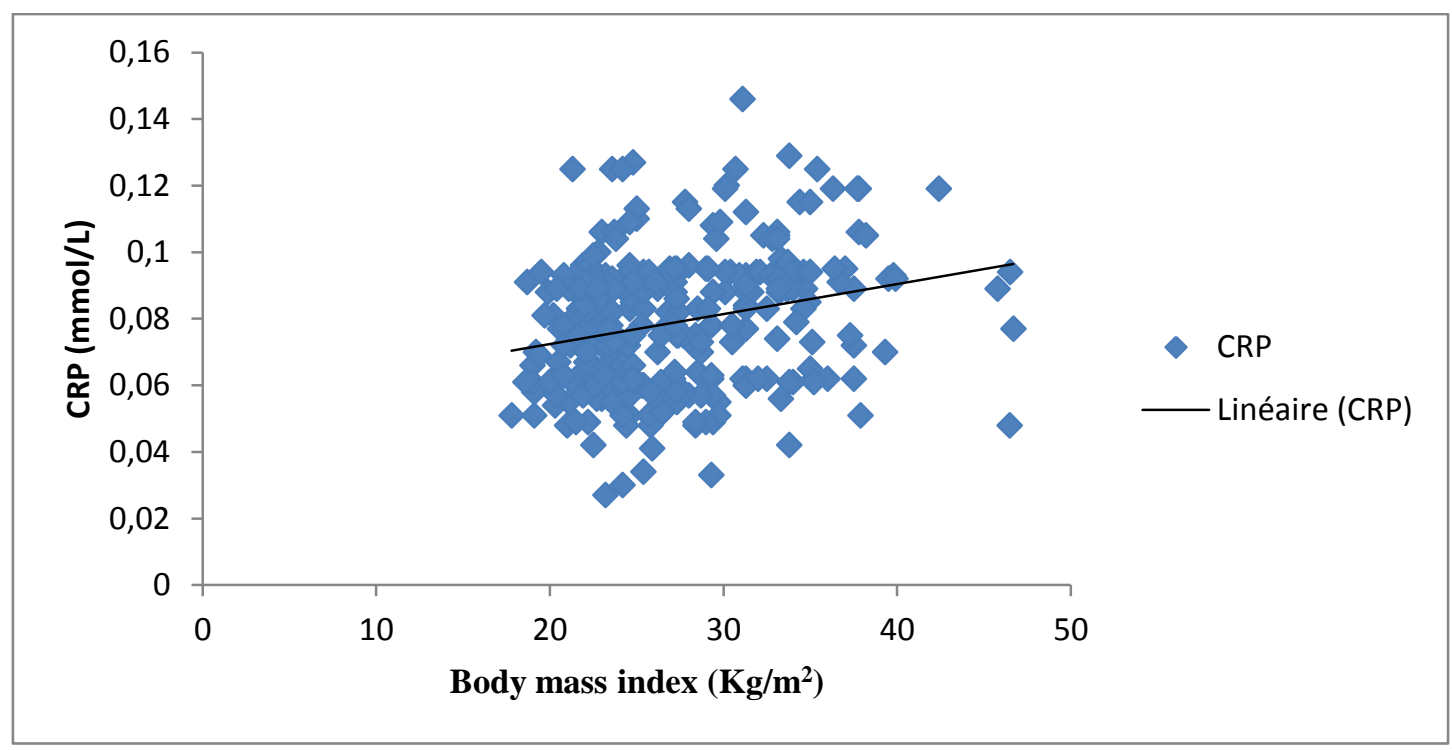

Figure 2: Scatter plot between body mass index and C-reactive protein in hypertensive patients $(\mathrm{n}=316, \mathrm{r}=0.251, \mathrm{p}<0.001)$.

\section{DISCUSSION}

In the current study, the increased levels of CRP in hypertensive patients is consistent with the observations of previous studies (Bautista et al., 2001; Susan et al., 2005; Shafi et al., 2010; Rajesh et al., 2013). This may be attributed to residual inability of the endothelium to produce nitric oxide and prostacyclin resulting to the loss of the vasodilator, antithrombotic and antiatherogenic properties of the vascular endothelium. High BP may in turn induce inflammation and raised CRP levels. Increased BP is also implicated in the promotion of reactive oxygen species generation as evidenced by a significant association between CRP and mononuclear oxidative stress (Yasunari et al., 2002; Shafi et al., 2010).

This alteration is important in the pathogenesis of hypertension and coronary heart disease. Wang et al. (2003) in their study showed that CRP up-regulates angiotensin II type I receptors in smooth muscle cells. This could result in vasoconstriction and subsequent elevation of BP. In vitro studies also indicates that hypertension can stimulate the release of inflammatory cytokines secondary to biochemical activation, upregulation of monocyte chemo-attractant protein-1 and generation of oxygen species (Susan et al., 2005).

In untreated human hypertension, CRP levels have been found to be increased dependent on systolic BP levels (Mathias et al., 2006). An increase in CRP levels is independently associated with elevated SBP and pulse pressure (but not DBP), as well as with other classical cardiovascular risk factors (Mathias et al., 2006). CRP is also a strong risk factor for ischemic stroke, independent of the severity of the underlying atherosclerotic event (Mathias et al., 2006).

The possible mechanisms of elevated serum CRP levels and its effect on hypertension could be as a result of endothelial dysfunction. Sinisalo et al. (2000) have shown that the levels of CRP are an independent determinant of endotheliumdependent vascular function among patients with coronary heart disease. Brief exposure of human subjects to endotoxin and inflammatory cytokines resulting in a glucocorticoid-inhabitable attenuation in the endothelium-dependent venous relaxation response, that took 7 days to recover (endothelia's 'stunning') has previously been demonstrated (Bautista et al., 2001). The endothelial 'stunning' could be the consequence of the ability of proinflammatory 
cytokines to inhibit agonist-stimulated generation of nitric oxide and prostacyclin by constitutive enzymes in the endothelial cell (Bautista et al., 2001). The residual inability of the endothelium to produce nitric oxide and prostacyclin results in the loss of the vasodilator, antithrombotic and antiatherogenic properties of the vascular endothelium. This alteration is important in the pathogenesis of hypertension and coronary heart disease (Bautista et al., 2001).

Elevated levels of CRP, in hypertension could be related to increased levels of biochemical markers of endothelial dysfunction such as plasma levels of von Willebrand factor and tissue plasminogen activator but not due to the titre of antibodies to Helicobacter pylori, Cytomegalovirus or Chlamydia pneumonia. Therefore, noninfectious environmental and genetic factors could result in chronically elevated levels of CRP and hypertension (Bautista et al., 2001).

The increased level of plasma fibrinogen among hypertensive patients as observed in the current study is consistent with the previous reports (Coban et al., 2004; Anoop et al., 2006). This could be secondary to increase in shear stress, endothelial dysfunction and progressive vascular disease in hypertension. Several plausible mechanisms could explain an observed association between elevated fibrinogen levels and hypertension, including the relation of fibrinogen to increased viscosity and peripheral vascular resistance, hyperinsulinaemia and insulin resistance (Anoop et al., 2006). Plasma fibrinogen is also influenced by many factors. The level increases with age, BMI, smoking, and diabetes mellitus (DM) and post menopause, and is related to fasting serum insulin, low density lipoprotein cholesterol (LDL-C), lipoprotein (a) and leukocyte count. Conversely, it decreases with moderate alcohol intake, physical activity, increased high density lipoprotein cholesterol (HDL-C), and with hormone replacement therapy (Sesso et al., 2003).

The current study demonstrates that, plasma fibrinogen is positively correlated with BMI in hypertensive subjects; this finding indicates that plasma fibrinogen increases with increased BMI (Anoop et al., 2006), while it is not significantly correlated with age and blood pressure. Similarly CRP positively correlated with BMI and was not significantly correlated with age and BP in hypertensive patients.

\section{Conclusion}

The results of the present study confirm that serum CRP and plasma fibrinogen levels are elevated in hypertension and positively correlated with BMI among hypertensive patients. Prospective cohort studies aimed at evaluating the potential benefits of CRP and fibrinogen in the diagnosis, prediction and management of hypertensive patients is hereby suggested.

\section{COMPETING INTERESTS}

Authors have declared that no competing interest exist.

\section{AUTHORS' CONTRIBUTIONS}

This work was carried out in collaboration between all the authors. MHY, SAA and SAI designed the study. BMY and MHY managed, analyzed samples and performed the statistical analysis, and wrote the first draft of the manuscript. All the authors read and approved the final manuscript.

\section{ACKNOWLEDGMENTS}

We thank all the staff of Cardiology Clinics of Usmanu Danfodiyo Teaching Hospital and Specialist Hospital, Sokoto, Nigeria, where samples for this study were collected. Our acknowledgements to the staff of Chemical Pathology Laboratory of Usmanu Danfodiyo University Teaching Hospital, Sokoto for their assistance in the analysis of the samples. We are also grateful to the staff of Chemical Pathology, School of Medical Laboratory Sciences, Usmanu Danfodiyo University, Sokoto, for their support towards the success of this study.

\section{REFERENCES}

Addo J, Smeeth L, Leon DA. 2007. Hypertension in sub-Sahara Africa: a systemic review. Hypertens., 
50(6):1012-1018.

DOI:

10.1161/hypertensionaha.107.093336.

Anoop S, Jie JW, Elena R, Paul M. 2006. Positive Association between Plasma Fibrinogen Level and Incident Hypertension among Men PopulationBased Cohort Study. Hypertens., $\quad 48$ : 1043-1049.

DOI: 10.1161/01.HYP.0000245700.13817.3c.

Bautista LE, Atwood JE, O'Malley PG, Taylor AJ. 2004. Association between Creactive protein and hypertension in healthy middle-aged men and women. Coron. Artery. Dis., 15:331336. DOI: 10.1161/JAHA.115.001802.

Bautista LE, Lopez-Jaramillo P, Vera LM, Casas JP, Otero AP, Guaracao AI. 2001. Is $\mathrm{C}$-reactive protein an independent risk factor for essential hypertension? $J$ Hypertens., 19: 857-861. PMID: 11393667.

Bautista LE, Vera LM, Arenas IA, Gamarra G. 2005. Independent association between inflammatory markers (Creactive protein, interleukin-6, and TNFalpha) and essential hypertension. $J$. Hum. Hypertens., 19:149-154. DOI:10.1038/sj.jhh.1001785.

Chard T. 1990. An introduction to radioimmunoassay and related techniques $\left(4^{\text {th }}\right.$ edn $) . \quad$ Amsterdam: Elsevier; 103-105.

Coban E, Ozdogan M, Akcit F. 2004. Levels of plasma fibrinogen and D-dimer in subjects with white-coat hypertension. $J$. Hum. Hypertens., 18: 291-292. DOI:10.1038/sj.jhh.1001670.

Danesh J, Wheeler JG, Hirschfield GM, Eda S, Eiriksdottir G, Rumley A. 2004. Creactive protein and other circulating markers of inflammation in the prediction of coronary heart disease. $N$. Engl. J. Med., 350: 1387-1397. DOI: 10.1056/NEJMoa032804.

Goyal R, Sarwate N. 2014. A Correlative study of hypertension with lipid profile. Int. J. Research appl. Natur. Soci. Sci., 2(2):143-150.

Hajat C, Dundas R, Stewart JA, Lawrence E, Rudd AG, Howard R, Wolfe CD. 2001. Cerebrovascular risk factors and stroke subtypes: Differences between ethnic groups. Stroke,

32:37-42.

DOI: https://doi.org/10.1161/01.STR.32. 1.37.

Ijeh II, Ejike CECC, Okorie U. 2010. Serum lipid profile and lipid pro-atherogenic indices of a cohort of Nigerian adults with varying glycemic and blood pressure phenotypes. Int. J. Biol. Chem. Sci., 4(6): 2102-2112 DOI: http://dx.doi.org/10.4314/ijbcs.v4i6.6491 2.

Ikewuchi JC, Onyeike EN, Uwakwe AA, Ikewuchi CC. 2011. Weight reducing and hypocholesterolemic effects of aqueous extract of the leaves of Tridax procumbens Linn on subchronic salt-loaded rats. Int. J. Biol. Chem. Sci., 5(2): 680-687. DOI: http://dx.doi.org/10.4314/ijbcs.v5i2.7213

Isezuo SA. 2015. People Living with Hypertension. Inaugural Lecture. Published by the Central Coordinating Committee for Usmanu Danfodiyo University Sokoto Inaugural Lectures and Seminars.

Joint National Committee. 2003. The Seventh Report of the Joint National Committee (JNC) on Prevention, Detection, Evaluation, and Treatment of High Blood Pressure. JAMA., 289(19): 25602572. DOI:10.1001/jama.2560.19.2572.

Kamath S, Lip GYH. 2003. Fibrinogen: biochemistry, epidemiology and determinants. QJM. Int. J. med., 96(10): 711-729. DOI: http://dx.doi.org / 10.1093/qjmed/hcg 129.

Kearney PM, Whelton M, Reynolds K, Jiang H. 2004. Worldwide Prevalence of Hypertension: a Systemic Review. J. Hypertens., 22:11-19. DOI: 10.1097/01.hjh.0000098149.7095679.

Li JJ, Fang CH, Hui RT. 2005. Is hypertension an inflammatory disease? Med. Hypotheses., 64: 236-240. DOI: 10.1016/j.mehy.2004.06.017.

Mathias H, Andreas F, Thomas FL. 2006. Nitric Oxide in Hypertension. J. Clin. Hypertens., 8(12):17-28.

Onyeali EU, Onwuchekwa AC, Monago CC, Monanu MO. 2010. Plasma lipid profile of Wistar albino rats fed palm oilsupplemented diets. Int. J. Biol. Chem. 
Sci., 4(4): 1163-1169.

DOI:

http://dx.doi.org/10.4314/ijbcs.63052.

Osuji CU, Omejua EG, Onwubuya EI, Ahaneku GI. 2012. Serum Lipid Profile of Newly Diagnosed Hypertensive Patients. Int. J. Hypertens., 2012:7. DOI: http://dx.doi.org/10.1155/2012/710486.

Pockley AG, De Faire U, Kiessling R, Lemne C, Thulin T, Frostegard J. 2002. Circulating heat shock protein and heat shock protein antibody levels in established hypertension. J. Hypertens., 20:1815-1820. DOI: 10.1097/00004872200209000- 00027.

Rajesh K, Suchet Sonia K. 2013. C-reactive protein and severity of hypertension. $J$. Advance Resear. Biol. Sci., 5(4): 331335.

medresearch.in/index.php/IJMRR/article /view/605.

Reshma S, Vasudha KC, Prasad ALS. 2011. High-sensitivity C-reactive protein, lipid profile, malondialdehyde and total antioxidant capacity in psoriasis. Int. J. Biol. Chem. Sci., 5(4): 1394-1402. DOI: http://dx.doi.org/10.4314/ijbcs.v5i2.7213

Schmaier AH. 2012. Laboratory evaluation of haemostatic and thrombotic disorders. In Haematology: Basic Principles and Practical ( $6^{\text {th }}$ edn), Hoffman R, Benz EJ, Silberstein LE, Heslop HE, Weitz JI, Anastasi J (eds). Elsevier Sounders: Philadelphia, PA; chapter 131.

Sergio S, Carmen G, Maria XD, Teresa J, Alma RC, Sandra R. 2007. Anthropometric measures and nutritional status in a healthy elderly population. BMC Public Heath, 7:2.

DOI: 10.1186/1471-2458-7-2.

Sesso HD, Jim enez MC, Wang L, Ridker PM, Buring JE, Gaziano JM. 2015. Plasma inflammatory markers and the risk of developing hypertension in men. J. Am. Heart Assoc., 4: e001802. DOI: 10.1161/JAHA.115.001802).

Sesso HD, Buring JE, Rifai N, Blake GJ, Gaziano JM, Ridker PM. 2003. C- reactive protein and the risk of developing hypertension. JAMA, 290:2945-2951. DOI: 10.1001/jama.290.22.2945.

Shafi MD, Pandith AA, Sameer AS, Sultan M, Yousuf A, Mudassar S. 2010. Hs-CRP: A potential marker for hypertension in Kashmiri population. Ind. J. Clin. Biochem., 25(2):208-212.

DOI: $10.1007 / \mathrm{s} 12291-010-0037-7$.

Sinisalo J, Paronen J, Mattila KJ, Syrjala M, Alfthan G, Palosuo T. 2000. Relation of inflammation to vascular function in patients with coronary heart disease. Atheroscler., 149: 403-411. https://books.google.com.ng/books?isbn $=0080527655$.

Sokoto State Business Directory. 2007. A Publication of the Commerce Department, Ministry of Commerce, Industry and Tourism, Sokoto; 14-18.

Lakoski SG, Cushman M, Palmas W, Blumenthal R, D'Agostino RB Jr, Herrington DM. $2005 . \quad$ The relationship between blood pressure and C-reactive protein in the Multi-Ethnic Study of Atherosclerosis (MESA). $J$. Am. Coll. Cardiol., 46(10):1869-1874. DOI:10.1016/j.jacc.2005.07.05 United Nation Population Fund. 2013. Sokoto State population projection, UNFPA, Nigeria.

Wang CH, Li SH, Weisel RD. 2003. Creactive protein up-regulates angiotensin type 1 receptors in vascular smooth muscle. Circulation, 107: 1783-1790. DOI:

https://doi.org/10.1161/01.CIR.0000061 916.95736.E5

Yasunari K, Maeda K, Nakamura M, Yoshikawa J. 2002. Oxidative stress in leukocytes is a possible link between blood pressure, blood glucose and Creactive protein. Hypertens., 39 : 777-780.

DOI: https://doi.org/10.1161/hy0302.104 670. 